\title{
Regulation by endogenous opioids of suckling-induced prolactin secretion in pregnant and lactating rats: role of ovarian steroids
}

\author{
M Soaje, E G de Di Nasso and R P Deis \\ Laboratorio de Reproducción y Lactancia, Cosejo Nacional de Investigaciones Cientificas y Técnicas, Casilla de Correo 855, 5500 Mendoza, Argentina \\ (Requests for offprints should be addressed to M Soaje; Email: msoaje@lab.cricyt.edu.ar)
}

\begin{abstract}
Evidence suggests that endogenous opioid peptides are implicated in the suckling-induced prolactin rise. We explored the role of the opioid system and the participation of ovarian hormones in the regulation of prolactin induced by the suckling stimulus at the end of pregnancy in rats with developed maternal behavior, and during lactation. Suckling for $24 \mathrm{~h}$ induced a significant increase in serum prolactin on day 19 of pregnancy, which was increased more than three times when naloxone $(2 \mathrm{mg} / \mathrm{kg}$ s.c.) or mifepristone $(2 \mathrm{mg} / \mathrm{kg})$ was administered. The combination of naloxone and mifepristone did not increase serum prolactin more than either compound alone. Administration of tamoxifen $(500 \mu \mathrm{g} / \mathrm{kg}$ orally) on days 14 and 15 of pregnancy completely abolished the effect of naloxone, indicating a role for estrogens in establishing this inhibitory role of opioids. To examine the participation of the opioid system during lactation, we used groups of rats on days 1 , 3, 5, 12 and 19 postpartum either (i) isolated from the pups for $4 \mathrm{~h}$, or (ii) isolated from the pups for $3.5 \mathrm{~h}$ and reunited with them and suckled for $30 \mathrm{~min}$. Naloxone, given just before replacing the pups, prevented the increase in serum prolactin levels observed in the suckled group of rats but had no effect on the basal levels of the isolated rats. To
\end{abstract}

examine whether the participation of the opioid system in the release of prolactin is dependent on the variation of progesterone levels, rats on day 20 of pregnancy were implanted with two cannulae containing progesterone (that blocked postpartum ovulation) or cholesterol, and cesarean surgery was performed on day 21 . To maintain lactation, pups (1-3 days old) were replaced every $24 \mathrm{~h}$, and 4 days after the cesarean eight pups were placed in the cage at $1800 \mathrm{~h}$ to maintain a strong suckling stimulus during the following $24 \mathrm{~h}$. Naloxone administration significantly reduced serum prolactin levels in control (cholesterol) rats but progesterone implants prevented the inhibitory effect of naloxone and this effect was not modified by treatment with estrogen.

These results indicate that the opioid system modulates suckling-induced prolactin secretion, passing from an inhibitory action before delivery to a stimulatory action during lactation. This regulatory shift seems to be dependent on the fall in progesterone concentration at the end of pregnancy and the subsequent increase after the postpartum ovulation and luteal phase.

Journal of Endocrinology (2002) 172, 255-261

\section{Introduction}

Endogenous opioid peptides play a role in the regulation of prolactin secretion in rats during proestrus (Ieri et al. 1980), stress (Rossier et al. 1979) and pregnancy (Sagrillo \& Voogt 1991, Soaje \& Deis 1994, 1997). Additionally, the participation of endogenous opioid peptides in the regulation of prolactin release in lactating rats has been reported by several authors (Ferland et al. 1978, Selmanoff \& Gregerson 1986, Baumann \& Rabii 1991, Arbogast \& Voogt 1998). Various studies have revealed that progesterone has an inhibitory control on prolactin release at the end of pregnancy (Vermouth \& Deis 1972, 1974, Jahn et al. 1986). In a previous paper (Soaje \& Deis 1994) we showed that preventing the central inhibitory action of progesterone on prolactin release by the antiprogesterone mifepristone (Philibert 1985) at the end of pregnancy facilitated the release of prolactin and this effect was enhanced by the administration of the opioid antagonist naloxone. Our previous results demonstrated a dual neuromodulatory regulation of prolactin secretion by the opioid system during pregnancy. After a stimulatory action during the first days, there is a change to an inhibitory control of prolactin secretion starting around day 16 (Soaje \& Deis 1994, 1997).

Suckling is one of the most powerful stimuli for prolactin release in mammalian species. It has been shown that suckling is associated with an inhibition of tyrosine hydroxylase (TH) activity in the arcuate nucleus (Wang et al. 1993, Arbogast \& Voogt 1998) and a decrease in tuberoinfundibular dopaminergic (TIDA) neuronal activity (Selmanoff \& Wise 1981, Demarest et al. 1983). 
Deis et al. (1989) demonstrated that the central antiprogesterone actions of mifepristone in pregnant rats are not strong enough to induce prolactin secretion alone, but are sufficient to potentiate the effect of suckling as a prolactin releaser.

The endogenous opioid peptides have also been implicated in the suckling-induced prolactin secretion. Arbogast \& Voogt (1998) reported that opioidergic input was essential for normal lactation due to its effect on the TIDA neurons. It seems that endogenous opioid peptides decrease neuronal TIDA activity during lactation, in part, by suppressing $\mathrm{TH}$ gene expression.

For many years our laboratory has been interested in exploring the inhibitory action of progesterone on prolactin secretion at the end of pregnancy. The primary goal of this study was to establish if there is any correlation between the changes in progesterone concentration that occur during pregnancy and lactation and the action of the endogenous opioid peptides in suckling-induced prolactin secretion. We also investigated the role of estrogen in this regulation.

\section{Materials and Methods}

\section{Animals}

Virgin female rats, 3-4 months old (200-220 g), bred in our laboratory and originally of the Wistar strain were used. They were kept in a light-controlled (lights on 0600-2000 h) and temperature-controlled $\left(22 \pm 2{ }^{\circ} \mathrm{C}\right)$ room; rat chow (Cargill, Córdoba, Argentina) and tap water were freely available. Vaginal smears were taken daily; virgin rats showing two or three consecutive 4 day cycles were selected. Rats were made pregnant by being caged individually with a fertile male on the night of proestrus. Vaginal smears were checked for the presence of spermatozoa on the following morning and this day was designated day 0 of pregnancy. Rats from our colony normally deliver on day 22 of pregnancy. This day was considered day 0 of lactation. After delivery the litters were adjusted to eight pups and they were handled daily until the day of the experiment. Pregnant rats with developed maternal behavior and lactating rats were used. The experiments were performed in accordance with the Guidelines on the Handling and Training of Laboratory Animals (The Biological Council, UFAW 1992).

\section{Development of maternal behavior in pregnant rats}

To study the effect of the suckling stimulus at the end of pregnancy, we used rats with induced maternal behavior. The development of maternal behavior of pregnant rats was performed as previously described (Deis et al. 1989). Briefly, virgin female rats showing regular 4 day cycles were introduced into special maternal cages (Gonzalez \&
Deis 1986) on diestrus day 2 at $1800 \mathrm{~h}$. On the following proestrus, a male and three 1- to 3-day-old freshly nourished young were introduced at $1800 \mathrm{~h}$ into the maternal cage. The morning after mating, if spermatozoa were found in the vaginal smears, was considered as day 0 of pregnancy. The male was removed from the cage and the pups replaced by recently fed pups every $12 \mathrm{~h}$. After development of maternal behavior, the rats were kept with pups for 5 days to consolidate maternal experience. After a period of 10-12 days without pups, the rats were provided with foster young to reinforce the development of the maternal behavior. This procedure is quite adequate to provide the stimulus of suckling at any time of pregnancy. The well-developed nipples in the mammary glands on day 18 of pregnancy facilitate the establishment of suckling. All the rats used showed evidence of suckled nipples during the experiment.

\section{Experimental procedures}

Experiment 1 This experiment was designed to determine whether naloxone administration, in association with the suckling stimulus, applied during late pregnancy is able to induce prolactin secretion with or without previous treatment with mifepristone. Rats on day 19 of pregnancy with or without induced maternal behavior were used. A litter of eight pups (4-6 days old) was introduced into the maternal cages at $1800 \mathrm{~h}$ on day 18 of pregnancy and they remained with the pregnant rats with induced maternal behavior for the next $24 \mathrm{~h}$. The opioid antagonist naloxone (2 mg/kg i.p.) (Sigma Chemical Co., St Louis, MO, USA) or saline was administered at $1730 \mathrm{~h}$ to rats pre-treated with mifepristone dissolved in corn oil $(2 \mathrm{mg} / \mathrm{kg}$ s.c.) or vehicle at $0800 \mathrm{~h}$. The animals were decapitated $30 \mathrm{~min}$ after treatment with naloxone or saline, blood samples were allowed to clot at room temperature and serum was separated and stored frozen $\left(-30{ }^{\circ} \mathrm{C}\right)$ until assayed for prolactin and progesterone.

Experiment 2 This experiment was performed to determine the role of estrogen and the opioid system in rats with the suckling stimulus applied at the end of pregnancy. Based on our previous results (Soaje \& Deis 1997), tamoxifen citrate (Gador S.A., Buenos Aires, Argentina) was dissolved in $0.14 \mathrm{M} \mathrm{NaCl}, 0.5 \%(\mathrm{v} / \mathrm{v})$ Tween 80 and administered orally at a dose of $500 \mu \mathrm{g} / \mathrm{kg}$ body weight at $1200 \mathrm{~h}$ on days 14 and 15 of pregnancy. Eight pups were introduced into the maternal cages at $1800 \mathrm{~h}$ on day 18 of pregnancy and remained with the pregnant rats for the next $24 \mathrm{~h}$. On day 19 of pregnancy, saline or naloxone was administered at $1730 \mathrm{~h}$ and blood samples were obtained by decapitation $30 \mathrm{~min}$ afterwards.

Experiment 3 To evaluate the participation of the opioid system during lactation, groups of lactating rats on days 1 , 3, 5, 12 and 19 were isolated from the litter at $1400 \mathrm{~h}$. 
Immediately before the replacement of the pups at $1730 \mathrm{~h}$, naloxone or saline was administered. After a suckling period of $30 \mathrm{~min}$, the mothers were decapitated and blood samples were obtained for determination of serum concentration of prolactin and progesterone.

Experiment 4 At the end of pregnancy there is a fall in serum progesterone concentration with a simultaneous increase in serum estrogen levels that is necessary to induce an increase in serum prolactin concentration, lactogenesis and parturition. After postparturition ovulation, serum progesterone levels increase and remain elevated during lactation. The present experiment was designed to examine whether the participation of the opioid system in the release of prolactin may be dependent on the decrease of progesterone levels that occurs before labor and the increase during lactation. Rats on day 20 of pregnancy were implanted s.c. at $1800 \mathrm{~h}$ with two silastic cannulae containing progesterone to maintain elevated serum levels of this steroid. Twenty-four hours later, a cesarean was performed and six pups (1-3 days old) obtained from lactating donor mothers were introduced into the cage to induce maternal behavior. The pups were replaced every $24 \mathrm{~h}$. Four days after cesarean surgery a litter of eight young (4-6 days old) was introduced into the cage at $1800 \mathrm{~h}$ to maintain a strong suckling stimulus during the following $24 \mathrm{~h}$. The control animals were implanted with silastic cannulae containing cholesterol. Naloxone $(2 \mathrm{mg} / \mathrm{kg})$ or saline was administered at $1730 \mathrm{~h}$ on day 5 after parturition and blood samples were obtained by decapitation $30 \mathrm{~min}$ afterwards.

Another group of hormone-implanted rats on the same schedule was treated s.c. with 5 or $10 \mu \mathrm{g} / \mathrm{rat}$ estradiol benzoate (Schering, Buenos Aires, Argentina) on days 1 and 3 of lactation respectively.

\section{Prolactin and progesterone determinations}

Prolactin was measured by a double-antibody RIA using materials generously provided by the National Hormone and Pituitary Program of the US National Institute of Diabetes, Digestive and Kidney Diseases (NIDDK) (Bethesda, MD, USA). Prolactin was radioiodinated using the chloramine $\mathrm{T}$ method (Niswender et al. 1969) and purified by passage through Sephadex G-75 and polyacrylamide agarose (ACA 54; LKB, Bromma, Sweden) columns. The assay sensitivity was $1 \mathrm{ng} / \mathrm{ml}$ serum and the inter- and intra-assay coefficients of variation were less than $10 \%$. Serum progesterone was measured using an RIA developed in our laboratory (Bussmann \& Deis 1979) with an antiserum raised in a rabbit against progesterone11-BSA conjugate. Assay sensitivity was less than $3 \mathrm{ng} / \mathrm{ml}$ serum and the inter- and intra-assay coefficients of variation were less than $10 \%$. Prolactin does not cross-react with placental lactogen (Robertson \& Friesen 1981).

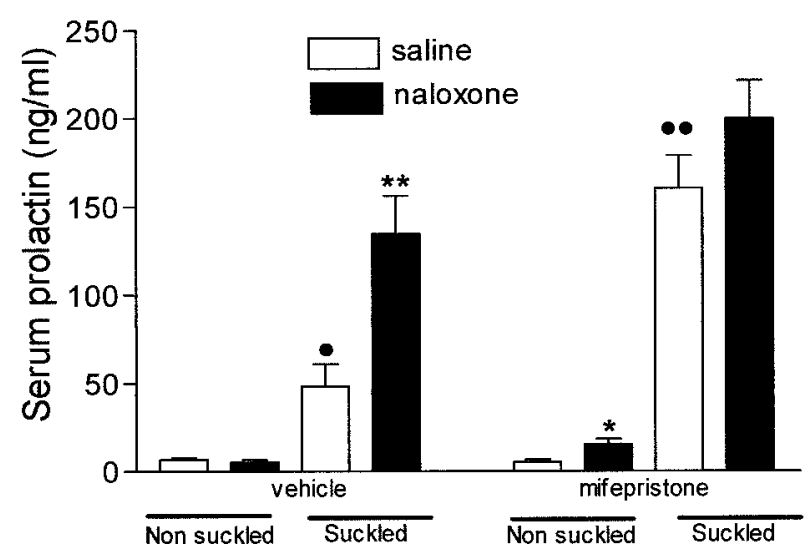

Figure 1 Effect of saline or naloxone on serum prolactin concentration on day 19 of pregnancy in non-suckled and suckled rats pre-treated with oil vehicle (v) or mifepristone. Results are means \pm S.E.M. of groups of $7-12$ animals. $P<0.05$ compared with non-suckled rats treated with vehicle plus saline. ${ }^{* *} P<0 \cdot 01$ compared with suckled rats treated with vehicle plus saline. ${ }^{*} P<0 \cdot 05$ compared with non-suckled rats treated with mifepristone plus saline. $P<0.01$ compared with suckled rats treated with mifepristone plus saline.

\section{Statistics}

Statistical evaluations were performed using Student's $t$-test to assay significant differences between means of two groups. One-way ANOVA followed by Tukey's test was used for multiple comparisons. A value of $P<0.05$ was considered statistically significant (Snedecor \& Cochran 1967).

\section{Results}

Experiment 1. Serum prolactin levels after suckling stimulus applied on day 19 of pregnancy: effect of naloxone and mifepristone plus naloxone treatment

Confirming previous results from this laboratory (Soaje \& Deis 1994, 1997), naloxone administration to control rats did not modify serum prolactin levels while naloxone in rats pre-treated with mifepristone induced a slight but significant increase in serum prolactin levels (Fig. 1). Twenty-four hours of suckling induced a significant increase in serum prolactin, as previously described (Deis et al. 1989) and naloxone administration potentiated this increase more than 2-fold (Fig. 1). As previously shown (Deis et al. 1989), mifepristone administration induced an important increase in serum prolactin levels in rats with $24 \mathrm{~h}$ of suckling. However, this increase was not elevated further by naloxone treatment. There were no significant differences in serum progesterone concentrations in suckled rats after administration of mifepristone or naloxone (not shown). 
Experiment 2. Effect of tamoxifen administration on serum prolactin levels on day 19 of pregnancy in suckled naloxone-treated rats

The administration of tamoxifen on days 14 and 15 of pregnancy reduced to $13.96 \pm 6.84 \mathrm{ng} / \mathrm{ml}$ (S.E.M.) $(P<0 \cdot 05)$ the elevated serum prolactin levels observed in rats on day 19 of pregnancy after $24 \mathrm{~h}$ of suckling $(48.54 \pm 12.33 \mathrm{ng} / \mathrm{ml})$. This treatment also abolished the important prolactin increase observed after naloxone treatment in rats with $24 \mathrm{~h}$ of suckling $(146 \cdot 0 \pm 2.90 \mathrm{ng} / \mathrm{ml}$ vs $11.57 \pm 4 \cdot 13 \mathrm{ng} / \mathrm{ml} ; P<0 \cdot 01)$.

Experiment 3. Serum prolactin and progesterone concentrations in lactating rats: effect of naloxone treatment

In pup-deprived dams, serum prolactin concentrations were low on all the days of lactation studied and no effect of naloxone was observed (Fig. 2a). When the pups were isolated for $3.5 \mathrm{~h}$ from the mother and replaced for $30 \mathrm{~min}$, a significant rise in serum prolactin concentrations was observed on the selected days of lactation. Simultaneous administration of naloxone with the suckling stimulus prevented the increase in serum prolactin previously observed on all the experimental days (Fig. 2b).

The pattern of circulating progesterone measured at $1800 \mathrm{~h}$ on different days of lactation in mothers with continuous suckling was not modified by naloxone treatment (Fig. 2c).

Experiment 4. Effect of progesterone, estrogen and naloxone treatment on serum prolactin levels in rats on day 5 of lactation

In this experimental model, the fall of progesterone levels occurring at the end of pregnancy and the rise that occurs after postpartum ovulation was prevented by the s.c. implantation of silastic cannulae containing progesterone. The progesterone implants on day 20 of pregnancy were able to prevent postpartum ovulation since macroscopic examination of the ovaries showed absence of new corpora lutea, indicating an absence of estrogen effect. The ovaries of the cholesterol-implanted rats showed populations of new corpora lutea, and circulating progesterone levels on day 5 postcesarean were not different from those of normal lactating rats on the same day of lactation (not shown). Circulating prolactin in the dams bearing cannulae containing progesterone or cholesterol was similar to that of untreated rats on day 5 of lactation. Naloxone administration significantly reduced serum prolactin concentrations on day 5 of lactation (Fig. 3) in the dams implanted with cholesterol, but the reduction in serum prolactin levels induced by naloxone was prevented by the progesterone implants. Moreover, pre-treatment with estradiol of
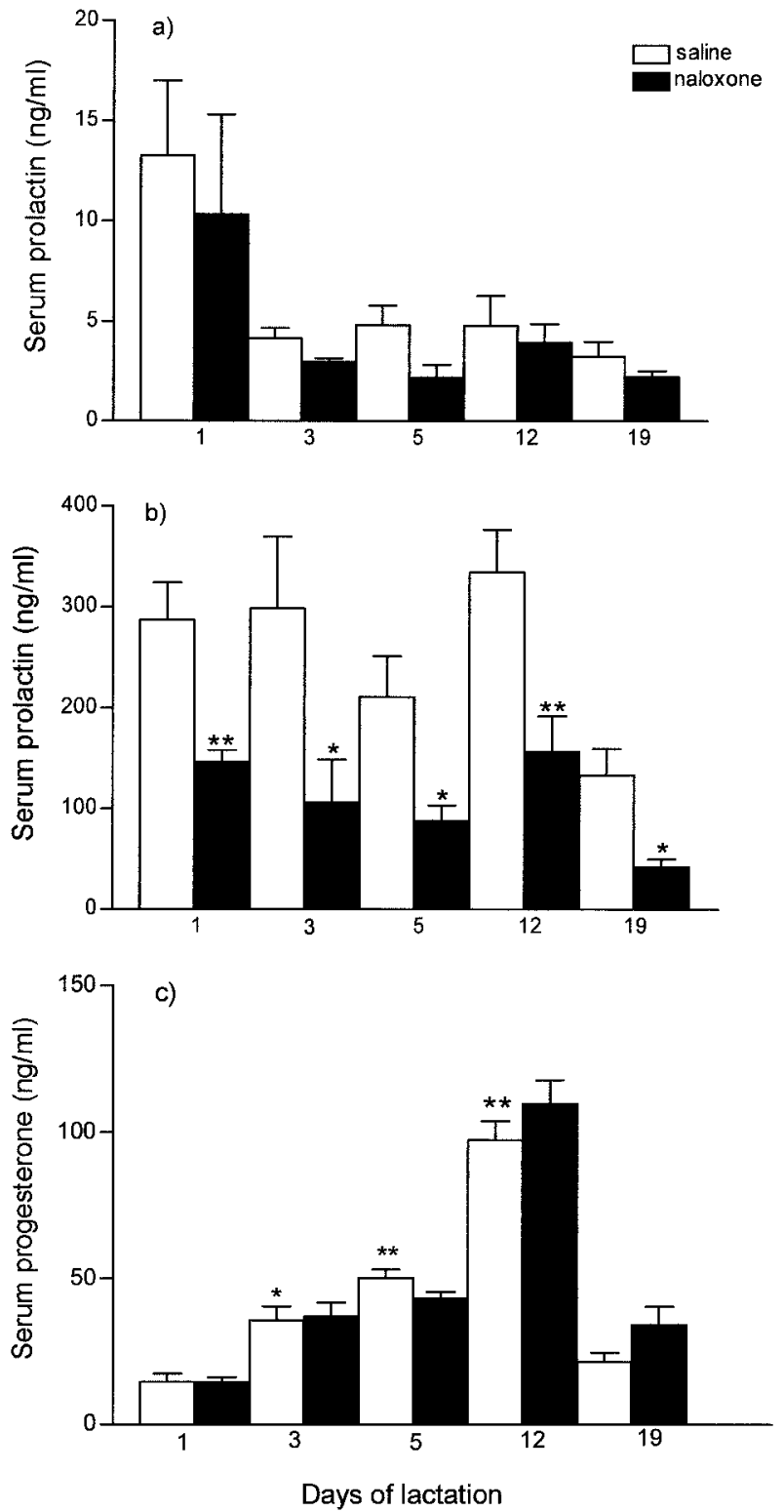

Figure 2 (a) Effect of saline or naloxone on serum prolactin concentration on days 1, 3, 5, 12 and 19 of lactation in pup-deprived dams. Results are means \pm S.E.M. of groups of 7-11 animals. There are no significant differences between salineand naloxone-treated rats. (b) Effect of saline or naloxone on serum prolactin concentration on days 1, 3, 5, 12 and 19 of lactation in pup-suckled dams. Results are means \pm S.E.M. of groups of 7-12 animals. ${ }^{*} P<0 \cdot 05,{ }^{* *} P<0 \cdot 01$ compared with the respective control. (c) Effect of saline or naloxone on serum progesterone concentration on days $1,3,5,12,19$ of lactation. Results are means \pm S.E.M. of groups of $7-12$ animals. ${ }^{*} P<0 \cdot 05,{ }^{* *} P<0 \cdot 01$ compared with day 1 and 19 .

progesterone-implanted rats had no effect on serum prolactin levels in saline- or naloxone-treated rats on day 5 of lactation. 


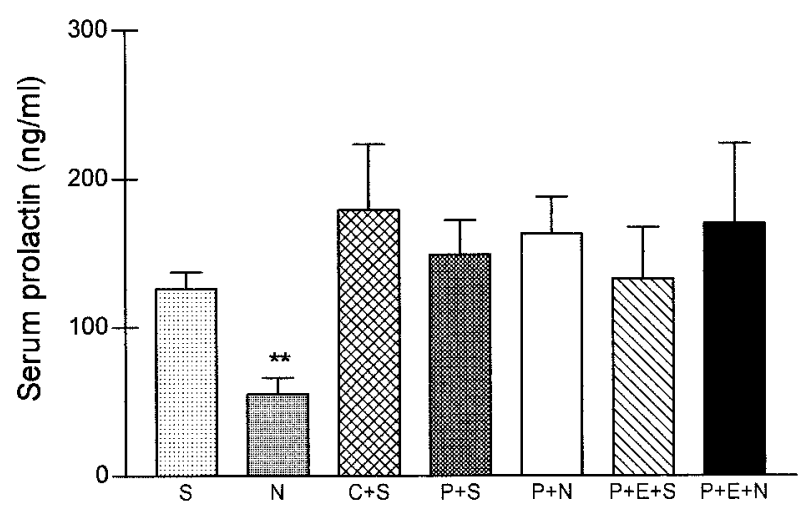

Figure 3 Effect of saline $(\mathrm{S})$ or naloxone $(\mathrm{N})$ on serum prolactin concentration in rats on day 5 of lactation after different treatment. $\mathrm{C}=$ cholesterol, $\mathrm{P}=$ progesterone, $\mathrm{P}+\mathrm{E}=$ progesterone plus estrogen. Results are means \pm S.E.M. of groups of 7-12 animals. ${ }^{* *} P<0 \cdot 01$ compared with $\mathrm{C}+\mathrm{S}$ (Student's $t$-test).

\section{Discussion}

Previous studies have demonstrated that progesterone acts centrally to prevent the release of prolactin at the end of pregnancy. Also, an inverse correlation between the secretion of progesterone and prolactin levels has been established (Vermouth \& Deis 1972, 1974, Jahn et al. 1986, Deis et al. 1989). Our present results show that the administration of naloxone significantly increased prolactin secretion in pregnant-suckled rats in spite of the elevated serum progesterone concentration. These results are in agreement with our earlier reports (Soaje \& Deis 1994, 1997) where the administration of mifepristone was not able to induce prolactin release but facilitated the inhibitory opioid regulation of prolactin release at the end of pregnancy. We have also demonstrated (Soaje et al. 1998) that administration of the antiprogesterone to rats on day 19 of pregnancy diminishes the turnover of dopamine in the medial basal hypothalamus. However, naloxone treatment after mifepristone administration did not modify the turnover of dopamine compared with mifepristone treatment alone. Given that an important increase in prolactin secretion was observed after naloxone administration to rats pre-treated with mifepristone (Fig. 1) (Soaje \& Deis 1994, 1997), we may suggest that a fall of the dopaminergic tone facilitates an inhibitory opioid effect exerted through a non-dopaminergic pathway. In fact, evidence suggests that progesterone may regulate TIDA neuronal activity. In adult rats in estrus, progesterone treatment increased the turnover of dopamine in the medial basal hypothalamus and preoptic area and diminished prolactin release through the activation of the dopaminergic system (Tomogane et al. 1990). Moreover, progesterone administration increases dopamine concentrations in portal blood (Cramer et al. 1979).

Several reports indicate that suckling-induced prolactin increase occurs due to a rapid and transient decrease in
TIDA activity (Selmanoff \& Wise 1981, Demarest et al. 1983, De Greef et al. 1987, Wang et al. 1993, Arbogast \& Voogt 1998), which sensitizes the lactotropes to releasing factors (Neill \& Nagy 1994). Comparing these findings with the present results, we may suggest that the suckling stimulus induces a decrease of dopaminergic tone that in turn facilitates naloxone action. In the present study, we also show that mifepristone is able to potentiate the stimulatory effect of suckling on prolactin release, confirming previous results (Deis et al. 1989). Thus, the central antiprogesterone action of mifepristone alone is not sufficient to induce prolactin secretion, but it is able to potentiate the effect of other prolactin releasers such as suckling. Interestingly in the present experiments, mifepristone administration induced an increase in serum prolactin levels only in suckled rats and this increase was not modified by naloxone treatment. In previous results obtained in our laboratory (Jahn \& Deis 1987, 1988, Soaje \& Deis 1994, 1997) we described an increase in serum prolactin levels at the end of pregnancy after serotoninergic or opioid antagonist administration. The increase in serum prolactin levels was no more than $150 \pm 50 \mathrm{ng} / \mathrm{ml}$. Since naloxone was not able to increase further the prolactin levels after mifepristone administration it is probable that the capacity of the hypophysis to release prolactin at the end of pregnancy is not very high when compared with lactating rats.

During pregnancy there is an increase in serum estrogen concentration on day 3, after which the steroid concentration remains very low until days 15-16 when it starts to increase progressively until parturition (Yoshinaga et al. 1969, Shaik 1971). Also, it is well known that estrogens stimulate the synthesis and the release of prolactin through an action at the hypothalamic and hypophyseal level (Chen \& Meites 1970). Moreover, it has been shown that the neurons of the arcuate nucleus responsible for producing opioid peptides are able to concentrate estrogen (Morrell et al. 1985, Jirikowski et al. 1986) and that estrogen regulates proopiomelanocortin gene expression (Wilcox \& Roberts 1985, Treiser \& Wardlaw 1992, Priest $\&$ Roberts 2000). An interesting finding from the present study is that the administration of tamoxifen on days 14 and 15 of pregnancy abolished the high prolactin levels observed in rats on day 19 of pregnancy with $24 \mathrm{~h}$ of suckling plus saline or suckling plus naloxone. Thus, the present and previous results (Soaje \& Deis 1997) indicate that the presence of estrogen on day 15-16 of pregnancy is an important hormonal factor for the activation of the opioid system as a neuromodulator of prolactin secretion at the end of pregnancy.

Administration of naloxone to lactating rats reduced the effect of acute suckling on serum prolactin concentrations on all the days studied. Quite a bit of evidence supports these results demonstrating a participation of the opioid system on suckling-induced hormone release (Ferland et al. 1978, Selmanoff \& Gregerson 1986, Baumann \& 
Rabii 1991). Moreover, Arbogast \& Voogt (1998) recently reported that opioidergic input is essential for normal lactation due to its effects on the TIDA neurons. It seems that the suckling-induced inhibition of TIDA neurons is mediated through the endogenous opioid peptides acting at $\mu$ - but not $\kappa$-opioid receptors (Callahan et al. 1996). In the present study, we found no correlation between the effect of naloxone and the various serum progesterone concentrations during lactation, indicating independence of the opioid system to changes in progesterone levels during lactation. However, our results suggest that the fall in serum progesterone concentrations at the end of pregnancy followed by the increase during lactation are necessary events to determine the opioid inhibition or opioid stimulation of prolactin release respectively. In our experimental model, we prevented the changes in circulating progesterone at the end of pregnancy and after postpartum ovulation with silastic cannulae that contained progesterone. The absence of new corpora lutea indicated the lack of postpartum ovulation and therefore the absence of estrogen action. Interestingly, no effect of naloxone on prolactin release was observed in these experimental groups. Since the administration of estrogen did not reverse the lack of effect of naloxone on prolactin release it would seem that estrogen does not participate in the action of the opioid on prolactin release during lactation. Thereby, we can suggest that the spontaneous fall in progesterone concentration at the end of pregnancy and its subsequent increase after postpartum ovulation are necessary for determining the role of the opioid system on prolactin release in lactating rats. However, further studies are necessary to establish this mechanism.

In conclusion, the present results support the proposal that endogenous opioid peptides are involved in the suckling-induced prolactin secretory response. We demonstrate that the suckling stimulus applied at the end of pregnancy is also subject to inhibitory modulation by opioids in the presence of high circulating levels of progesterone, while during lactation opioids mediate suckling-induced prolactin release in a stimulatory fashion. However, the shift from inhibitory to stimulatory action of the opioid system on prolactin secretion during lactation seems to be dependent on the characteristic changes in circulating progesterone levels at the end of pregnancy and during the first days of lactation.

\section{Acknowledgements}

This work was partially supported by a grant $05-00000$ 01930 from the Agencia Nacional de Promoción Cientí fica y Tecnológica, Argentina and from the Programa Latinoamericano de Capacitación e Investigación en Reproducción Humana (PLACIRH) (PLI-256/96; Re-entry grant PRE-005/96). M S, E G D N and R P D are members of CONICET. The authors are indebted to the Hormone Distribution Program, NIADDK, for kindly providing the materials for the prolactin RIA and to Dr R Milius of the National Institute of Mental Health (NIMH) Chemical Synthesis Program for providing mifepristone (RU 38486). The authors offer sincere thanks to Dr Virginia Calvo and Dr G Jahn for the revision of the manuscript.

\section{References}

Arbogast LA \& Voogt JL 1998 Endogenous opioid peptides contribute to suckling-induced prolactin release by suppressing tyrosine hydroxylase activity and messenger ribonucleic acid levels in tuberoinfundibular dopaminergic neurons. Endocrinology 139 2857-2862

Baumann M \& Rabii J 1991 Inhibition of suckling-induced prolactin release by $\mu$ - and $\kappa$-opioid antagonists. Brain Research 567 224-230.

Bussmann LE \& Deis RP 1979 Studies concerning the hormonal induction of lactogenesis by prostaglandin $\mathrm{F}_{2 \alpha}$ in pregnant rats. Journal of Steroid Biochemistry 11 1485-1489.

Callahan P, Baumann MH \& Rabii J 1996 Inhibition of tuberoinfundibular dopaminergic neural activity during suckling: involvement of $\mu$ and $\kappa$ opiate receptor subtypes. Journal of Neuroendocrinology 8 771-776.

Chen CL \& Meites J 1970 Effects of estrogen and progesterone on serum and pituitary prolactin levels in ovariectomized rats. Endocrinology 86 503-505.

Cramer OM, Parker CR Jr \& Porter JC 1979 Stimulation of dopamine release into hypophysial portal blood by administration of progesterone. Endocrinology 105 929-933.

De Greef WJ, Voogt JL, Visser TJ, Lamberts SW \& VanderSchoot P 1987 Control of prolactin release induced by suckling. Endocrinology $121316-322$.

Deis RP, Carrizo DG \& Jahn GA 1989 Suckling-induced prolactin release potentiates mifepristone-induced lactogenesis in pregnant rats. Journal of Reproduction and Fertility 87 147-153.

Demarest KT, McKay DW, Riegle GD \& Moore KE 1983 Biochemical indices of tuberoinfundibular dopaminergic neuronal activity during lactation: a lack of response to PRL. Neuroendocrinology 36 130-137.

Ferland L, Kledzik GS, Cusan L \& Labrie F 1978 Evidence for a role of endorphins in stress and suckling induced prolactin release in the rat. Molecular and Cellular Endocrinology 12 267-272.

Gonzalez DE \& Deis RP 1986 Maternal behavior in cycling and androgenized female rats: role of ovarian hormones. Physiology and Behavior 38 709-793.

Ieri T, Chen HT, Campbell GA \& Meites J 1980 Effects of naloxone and morphine on the proestrous surge of prolactin and gonadotropins in the rat. Endocrinology 106 1568-1570.

Jahn GA \& Deis RP 1987 A possible dual regulation of prolactin release by the serotoninergic system in rats at pro-oestrus and during late pregnancy: role of ovarian hormones. Journal of Endocrinology 112 367-374.

Jahn GA \& Deis RP 1988 Effect of serotonin antagonists on prolactin and progesterone secretion in rats: evidence that the stimulatory and inhibitory actions of serotonin on prolactin release may be mediated through different receptors. Journal of Endocrinology 117 415-422.

Jahn GA, Alonso N \& Deis RP 1986 Ovarian and fetoplacental factors and the regulation of prolactin release during pregnancy in the rat. Journal of Reproduction and Fertility 77 125-133.

Jirikowski GF, Merchenthaler I, Rieger GE \& Stumpf WE 1986 Estradiol target sites immunoreactive for $\beta$-endorphin in the arcuate and periventricular neurons. Neuroscience Letters 65 121-126.

Morrell JL, McGinty JD \& Pfaff DW 1985 A subset of $\beta$-endorphin or dynorphin containing neurons in the medial basal hypothalamus accumulates estradiol. Neuroendocrinology 41 417-426. 
Neill DJ \& Nagy GM 1994 Prolactin secretion and its control. In The Physiology of Reproduction, pp 1833-1860. Eds E Knobil \& JD Neill. New York: Raven Press.

Niswender GD, Chen CL, Midgley AR Jr, Meites J \& Ellis S 1969 Radioimmunoassay for rat prolactin. Proceedings of the Society for Experimental Biology and Medicine 130 793-797.

Philibert D, Moguilewsky M, Mary I, Lecaque D, Tournemine C, Secchi J \& Deraedt R 1985 Pharmacological profile of RU486 in animals. In The Antiprogestin Steroid RU486 and Human Fertility Control, pp 49-68. Eds EE Baulieu \& SJ Segal. New York: Plenum Press.

Priest CA \& Roberts JL 2000 Estrogen and tamoxifen differentially regulate beta-endorphin and cFos expression and neuronal colocalization in the arcuate nucleus of the rat. Neuroendocrinology 72 293-305.

Robertson MC \& Friesen HG 1981 Two forms of rat placental lactogen revealed by radioimmunoassay. Endocrinology 108 2388-2390.

Rossier J, French E, Rivier C, Shibasaki T, Guillemin R \& Bloom FE 1979 Stress-induced release of prolactin: blockade by dexametaxone and naloxone may indicate $\beta$-endorphin mediation. PNAS 77 666-669.

Sagrillo CA \& Voogt JL 1991 Endogenous opioids mediate the nocturnal prolactin surge in the pregnant rat. Endocrinology 129 925-930.

Selmanoff M \& Gregerson KA 1986 Suckling-induced prolactin release is suppressed by naloxone and stimulated by $\beta$-endorphin. Neuroendocrinology 42 255-259.

Selmanoff M \& Wise PM 1981 Decreased dopamine turnover in the median eminence in response to suckling in the lactating rat. Brain Research 212 101-115.

Shaik AA 1971 Estrone and estradiol levels in the ovarian venous blood from rats during estrous cycle and pregnancy. Biology of Reproduction 5 297-307.

Snedecor GW \& Cochran WG 1967. Statistical Methods. Ames, IA: Iowa State University Press.
Soaje M \& Deis RP 1994 A modulatory role of endogenous opioids on prolactin secretion at the end of pregnancy in the rat. Journal of Endocrinology 140 97-102.

Soaje M \& Deis RP 1997 Opioidergic regulation of the prolactin secretion during pregnancy: role of ovarian steroids. Journal of Endocrinology 154 99-106.

Soaje M, Bregonzio C, Cabrera R \& Deis R 1998 Efecto de dopamina en el rol modulador del sistema opioide sobre la secreción de prolactina al final de la preñez en la rata. Medicina 58592. Abstract 94.

Tomogane H, Mizoguchi K \& Yokoyama A 1990 Effects of progesterone on concentrations of monoamines in hypothalamic areas and prolactin levels in rats. Proceedings of the Society for Experimental Biology and Medicine 195 208-212.

Treiser SL \& Wardlaw SL 1992 Estradiol regulation of proopiomelanocortin gene expression and peptide content in the hypothalamus. Neuroendocrinology 55 167-173.

Vermouth NT \& Deis RP 1972 Prolactin release induced by prostaglandin F2 $\alpha$ in pregnant rats. Nature 238 248-250.

Vermouth NT \& Deis RP 1974 Prolactin release and lactogenesis after ovariectomy in pregnant rats: effect of ovarian hormones. Journal of Endocrinology 63 13-20.

Wang H-J, Hoffman GE \& Smith MS 1993 Suppressed tyrosine hydroxylase gene expression in the tuberoinfundibular dopaminergic system during lactation. Endocrinology 133 1657-1663.

Wilcox JN \& Roberts JL 1985 Estrogen decreases rat hypothalamic proopiomelanocortin messenger ribonucleic acid levels. Endocrinology 117 2392-2396.

Yoshinaga K, Hawkins RA \& Stocker JF 1969 Estrogen secretion by the rat ovary in vivo during the estrous cycle and pregnancy. Endocrinology 85 103-112.

Received in final form 28 September 2001 Accepted 22 October 2001 